\section{El estado}

y la iglesia

en Costa Rica.

Enfoque jurídico

Celín Arce Gómez*

\section{RESUMEN}

El presente artículo busca determinar si el Estado costarricense es confesional, puesto que la Constitución de 1949 declara que la religión católica es la del Estado. Para tales efectos se hace un análisis de la evolución histórica de dicha disposición, para concluir con un estudio sobre lo que informa la doctrina moderna y la jurisprudencia constitucional, a la luz de los principios cristianos de justicia social, sin dejar de analizar la naturaleza jurídica de la missio canónica.

\section{PALABRAS CLAVE}

Estado costarricense, Estado confesional, Constitución, Doctrina moderna, jurisprudencia constitucional, justicia social.

* Tiene una Licenciatura en Derecho por la Universidad de Costa Rica y un Doctorado en Derecho por la Universidad Estatal a Distancia. Actualmente es el Director de la Oficina Jurídica de la UNED. carce@uned.ac.cr

Rec. 8-5-08 Acep. 16-9-09

\section{ABSTRACT}

This article seeks to determine if the Costa Rican State is a state religion due to the fact that the Constitution of 1949 declares Catholic religion as the official one. To determine that, an analysis of the historical evolution of this provision is made, concluding with a study of what the modern doctrine and constitutional jurisprudence mention in the light of the Christian principles of social justice and while analyzing the legal nature of the canonical mission.

\section{KEYWORDS}

Costa Rican state, state religion, Constitution, Modern doctrine, constitutional jurisprudence, social justice.

INTRODUCCIÓN:

BREVERESEÑA HISTÓRICA

El artículo 76 de la Constitución Política vigente establece que: "La Religión Católica, Apostólica, Romana, es la del Estado, el cual contribuye a su mantenimiento, sin impedir el libre ejercicio en la República de otros cultos que no se opongan a la moral universal ni a las buenas costumbres".

¿Significa lo anterior que Costa Rica es un Estado confesional? En caso contrario ¿cómo debemos de 


\section{ESPIGA}

entender la razón de ser y la lógica de dicho numeral?

Por tanto nos proponemos a continuación a estudiar el contenido y alcances de ésta disposición.

En primer lugar conviene que repasemos, aunque sea de forma somera, la evolución constitucional de esta disposición, que no es otra cosa que exponer la evolución constitucional de las relaciones entre el Estado y la Iglesia Católica.

Se tiende a aceptar que la Constitución Española de Cádiz de 1812 fue la primera Constitución de Costa Rica, misma que en su artículo 12 decía:

“La Religión de la Nación española es y será perpetuamente la católica, apostólica, romana, única verdadera. La Nación la protege por leyes sabias y justas, y prohíbe el ejercicio de cualquier otra".

Podemos observar que, a partir del anterior texto, se inspiran nuestras sucesivas Constituciones, las que, inclusive, repiten literalmente aquella disposición.

El Pacto Social Fundamental Interino de Costa Rica del 1 de diciembre de 1821 declara que "La religión de la provincia es y será siempre la católica apostólica romana, como única verdadera, con exclusión de cualquiera otra". (Art. 3).

Como se puede apreciar repite casi literalmente la disposición de la Constitución de Cádiz, declarando que nuestro Estado es, consecuentemente confesional.

Poco después, el Primer Estatuto Político de la Provincia de Costa Rica del 17 de marzo de 1823, declara algo similar:

"La religión de la provincia es y será siempre exclusivamente la católica apostólica romana". (art. 7).

El Segundo Estatuto Político de la Provincia de Costa Rica del 16 de mayo de 1823, reitera en forma literal la disposición anterior, lo que también hace en su artículo 7.

La Constitución de la República Federal de Centro América del 22 de noviembre de 1824 preceptúa que:

“Su religión es: la católica apostólica romana, con exclusión del ejercicio público de cualquiera otra". (art. 11). 
Dicha Constitución es reformada en el año 1835 y en esta materia indica su artículo 11:

“Los habitantes de la república pueden adorar a Dios según su conciencia. El Gobierno general les protege en la libertad del culto religioso. Mas los Estados cuidarán de la actual religión de sus pueblos; y mantendrán todo culto en armonía con la leyes".

El 25 de enero del año 1825, se promulga la Ley Fundamental del Estado Libre de Costa Rica la que en su artículo 25 indica:

"La religión del Estado es la misma que la de la República, la Católica, Apostólica, Romana, la cual será protegida con Leyes sabias y justas".

Corresponde luego el turno a la Constitución Política del Estado de Costa Rica del 9 de abril de 1844, la que manda:

"El Estado libre de Costa Rica sostiene y protege la Religión Católica, Apostólica, Romana que profesan los costarricenses" (art. 54);

Y agrega su artículo siguiente:

“La potestad Eclesiástica en los asuntos que no sean de conciencia, obrará siempre en con- sonancia con la civil, y la ley determinará el modos y forma de verificarlo".

La Constitución Política del 10 de febrero de 1847 señala que:

"El Estado profesa la religión Católica Apostólica Romana, única verdadera: la proteje con leyes sabias y justas y no permite el ejercicio público de alguna otra" (art. 37). En su artículo 38 repite literalmente el artículo 55 de la Constitución anterior.

Esta Constitución es reformada en el año 1848, que es promulgada por Don José María Castro Madriz mediante el Decreto CLIX del 30 de noviembre, y su artículo 15 dice:

"La Religión Católica, Apostólica Romana es la de la República: el Gobierno la protege, y no contribuirá con sus rentas a los gastos de otro culto".

Dicha disposición la reitera en forma literal la Constitución del 27 de diciembre de 1859, que fue promulgada por José María Montealegre, en su artículo 6.

La Constitución Política del 15 de abril de 1869, promulgada por 


\section{ESPIGA}

Don Jesús Jiménez estipula en su artículo 5:

“La ReligiónCatólica,Apostólica, Romana es la de la República: el Gobierno la proteje y no contribuye con sus rentas a los gastos de otros cultos, cuyo ejercicio, sin embargo tolera".

Este artículo fue reiterado en el artículo 51 de la Constitución Política del 7 de diciembre de 1871 .

La efímera Constitución Política del 8 de junio de 1917, que fue derogada el 3 de setiembre de 1919, declaró que:

“La Religión Católica Apostólica Romana, es la del Estado, el cual contribuye a su mantenimiento, sin impedir el libre ejercicio de ningún otro culto que no se oponga a la moral universal ni a las buenas costumbres. La declaración a que se refiere este artículo no afecta la legislación existente, ni coarta en forma alguna la libertad de acción de los Poderes Públicos respecto de cualesquiera intereses nacionales".

Posteriormente se restablece la Constitución de 1871 la que, además de ser una de las que más vigencia ha tenido, fue la que sirvió de base a la Constituyente de 1949.
La Constitución de 1871, con las reformas y adiciones del año 1946, establece en la materia que nos ocupa:

“La Religión Católica, Apostólica Romana, es la del Estado, el cual contribuye a su mantenimiento, sin impedir el libre ejercicio en la República, de ningún otro culto que no se oponga a la moral universal ni a las buenas costumbres" (art. 66).

\section{El tema del Estado confesional en la Constituyente de 1949}

En la Asamblea Constituyente de 1949 el tema de la religión no fue polémico ni de mucha preocupación de los señores Diputados. Mas bien se instó a los mismos evitar discusiones entorno a este asunto y que se acogiera el artículo 66 de la Constitución de 1871 tal y como estaba, lo que, ciertamente, sucedió en la sesión n. ${ }^{\circ} 131$ del 17 de agosto de 1949.

Empero, el Diputado Zeledón indicó que hubiese preferido que dicho artículo dijese:

"Mientras la Religión Católica, Apostólica, Romana, sea la de la mayoría de la Nación, el Estado 
contribuirá a su mantenimiento, sin impedir el libre ejercicio en la República, de ningún otro culto que no se oponga a la moral universal ni a las buenas costumbres". ${ }^{1}$

Posteriormente en el mes de octubre el Diputado Vargas Castro presentó una moción para variar el artículo anterior ya aprobado para que dijese:

“Todos los habitantes de la República gozan de libertad de conciencia y del derecho de manifestar y propagar sus creencias religiosas y ejercitar el culto, individual o colectivamente, mientras no se ofendan los sentimientos morales de la sociedad".

El Diputado Volio Sancho, quien se caracterizó por defender los intereses y la visión de la Iglesia Católica, no solo en esta materia sino que también en la educativa, se opuso a la anterior moción por lo que a la postre no prosperó.

“...expresó que había sido una actitud de gran prudencia la asumida por la Asamblea al no contrariar aquellas reglas de la

1. Actas Asamblea NacionalConstituyente. Imprenta Nacional, San José, 1957 T.III. pág. 114.
Constitución del setenta y uno, consagradas por el tiempo y que tienen el apoyo de la gran masa católica del país. La Asamblea ha dado muestras en varias ocasiones de esa prudencia, encaminada a evitar una lucha de carácter religiosa, indudablemente de pésimos resultados para el país. Ha habido el propósito de mantener el statu quo en materia religiosa, para no alterar, ni en la forma ni en el fondo, aquellas disposiciones que tradicionalmente han venido figurando en la Constitución y en la leyes de la República."2

Las actas recogen además de la participación del Diputado Volio Sancho la del Representante Trejos quien, igualmente, se opuso a la moción del Diputado Vargas Castro.

"No creo -dijo- que sea un despropósito asignarle al Estado una religión determinada, como lo ha afirmado el distinguido proponente. Una religión no es más que una filosofía de la vida. Las instituciones suelen basarse, más o menos directamente en algún punto filosófico. Al asignársele al Estado una religión, significa que el Estado, vale decir, la institución del 
Estado, tiene un concepto filosófico de la vida. Es perfectamente razonable asignarle la Religión Católica Apostólica Romana, si ésta es la que profesa la inmensa mayoría de nuestro pueblo. Creo conveniente -concluyó el señor Trejos- mantener el artículo setenta y siete tal y como fue aprobado por esta Asamblea y que ha venido rigiendo desde los inicios de la República". ${ }^{3}$

Finalmente, en la sesión n. ${ }^{\circ} 180$ del 2 de noviembre de 1949 se aprueba el artículo tal y como se encuentra vigente a la fecha, con una ligera modificación de estilo respecto al artículo de la Constitución de 1871.4

\section{Tipología de relaciones entre el Estado y la Iglesia}

A partir del precepto bíblico dado por Jesucristo de "dar al César lo que es el César y a Dios lo que es Dios" (Mateo 22,21; Lucas 20,25 y Marcos 12,17), podemos decir

3. Ibídem pág. 522.

4. Ibídem pág. 612 "La Religión Católica, Apostólica Romana, es la del Estado, el cual contribuye a su mantenimiento, sin impedir el libre ejercicio en la República, de ningún otro culto que no se oponga a la moral universal ni a las buenas costumbres". que se ha dado diferentes formas de relación entre el Estado y las religiones o específicamente con la Iglesia Católica.

Por ejemplo, el "cesaropapismo" es aquel sistema en el cual el poder estatal ejerce un abusivo control sobre la Iglesia y los asuntos de la fe, la doctrina, la liturgia y la disciplina interior de los fieles. " La idea que está detrás del cesaropapismo es que, dado que los monarcas de derecho divino reciben su poder directamente de Dios, tienen la ineludible misión de velar por la salvación de las almas de sus súbditos, lo cual los lleva inmiscuirse en los asuntos dogmáticos y de culto de la Iglesia. ${ }^{5}$

En este modelo se da una subordinación tal de la Iglesia al Estado, que la primera llega a convertirse hasta en un órgano del Estado.

Ejemplo de este modelo fue Rusia en el tiempo de los zares, quienes mantuvieron siempre una posición predominante en la guía de la iglesia ortodoxa.

5. Borja. Rodrigo. Enciclopedia de la Política. Fondo de Cultura Económica. México.,1998. pág.103 
Situación similar se dio en la época de los Emperadores del Sacro Imperio romano.

Luego tenemos el "confesionalis$\mathrm{mo}^{\prime \prime}$, que es el contrario al anterior y consiste en la tendencia de someter la política al credo religioso. La religión invade los ámbitos del Estado e inspira los actos de la vida pública.

"Esto lleva a la implantación de una religión oficial, excluyente de toda otra, y al sometimiento total del poder político a los designios religiosos señalados por la Iglesia. Desaparece la libertad de cultos para quienes profesan otras religiones". ${ }^{6}$

Este modelo lo tuvo España, particularmente durante el período que va desde el final de la guerra civil hasta la aprobación de la Constitución de 1978.

Como una reacción en contra del confesionalismo surge el otro modelo conocido como " laicismo" que aboga por una separación entre el Estado y la Iglesia, por una total neutralidad o separación de las instituciones estatales y la libertad religiosa.

6. ibídem pag. 147
"El estado prescinde de todo credo religioso, no profesa religión alguna, observa una absoluta neutralidad ante el fenómeno religioso y considera que todas las creencias, como expresión de la íntima conciencia de las personas, son iguales y poseen idénticos derechos y obligaciones" ${ }^{\prime 7}$

La Constitución de la República italiana de 1948 configura un estado laico en sus principios fundamentales, en cuanto declara la irrelevancia jurídica de las convicciones religiosas de los individuos (art. 3), establece la independencia y la soberanía del Estado y la Iglesia Católica cada uno en su propio orden (art. 7) y reconoce la pluralidad de las confesiones religiosas dotadas de igual libertad (art. 8). ${ }^{8}$

Modernamente tiende a configurarse otro modelo que se ha dado en denominar como del "Estado democrático de libertad religiosa"9 y que da ini-

7. Ibídem. Pág. 570.

8. Zanone, Valerio. Laicismo. En Diccionario de Política. Bobbio y otros. Siglo Veintiuno Editores, México, 1991. T. II pág. 859.

9. Viladrich, Pedro-Juan. Los principios informadores del Derecho Eclesiástico Español. En Derecho Eclesiástico del Estado Español.. Ediciones Universidad de Navarra. Pamplona, 1983, pág 169 y ss. 


\section{ESPIGA}

cio en España con ocasión de la Constitución de 1978, la que quiebra la relación entre confesionalidad y laicidad estableciendo una nueva alternativa: consigna como su primer principio definidor del Estado en materia eclesiástica el principio de libertad religiosa, que sustituye tanto al principio de confesionalidad como al de laicidad para dar paso a una nueva concepción o producto de los dos anteriores, es decir, se rompe con la tradicional idea de concebir la confesionalidad o la laicidad del Estado como extremos opuestos de una misma línea, como alternativas contradictorias de un mismo nervio lógico.

Este modelo supera la idea tradicional de que la confesionalidad, laicidad y libertad religiosa son incompatibles y que no pueden existir para la misma suprema función.

Es el caso de España, a partir de la Constitución de 1978. "Pues bien, lo que nuestra Constitución señala a los poderes públicos es que al tener en cuenta el factor religioso, como factor social de la sociedad española, lo "tengan en cuanta" también con sus características reales y diferenciales: de un lado, su arraigo, importancia, tradición y extensión; de otro lado, sus peculiaridades o características orgánicas específicas. En suma, nuestra Constitución desea de los poderes públicos un trato específico del factor religioso."10

Nótese que este modelo no es confesional, puesto que el Estado no asume una fe religiosa ni siquiera la fe religiosa de la mayoría de la población, pero tampoco es un Estado laico en el sentido de que asuma una actitud de indiferencia y de pasividad ante el hecho religioso sino que, por el contrario, asume un papel activo frente al hecho religioso, puesto que no sólo lo reconoce y garantiza sino que impulsa o promueve jurídicamente el factor religioso.

\section{La libertad religiosa}

Independientemente del modelo que cada país adopte, ninguno de ellos puede ser entendido adecuadamente sin tener en mente el hecho religioso desde el punto de vista jurídico, esto es, sin considerar la libertad religiosa, por lo que conviene repasar, aunque sea someramente, los alcances de dicha libertad.

10. Ibídem pág. 234. 
La libertad de religión involucra, en primer lugar, la libertad de pensamiento en materia religiosa, llamada también libertad de conciencia, como la de culto y de proselitismo, es decir, la posibilidad de reunirse con otros fieles para hacer en común funciones, ceremonias y prácticas religiosas, y discutir problemas religiosos con el fin de propagar la fe.

La libertad religiosa encierra, en su concepto genérico, un haz complejo de facultades. En este sentido, en primer lugar se refiere al plano individual, es decir, la libertad de conciencia, que debe ser considerado como un derecho público subjetivo individual, esgrimido frente al Estado, para exigirle abstención y protección de ataques de otras personas o entidades. Consiste en la posibilidad, jurídicamente garantizada, de acomodar el sujeto, su conducta religiosa y su forma de vida a lo que prescriba su propia convicción, sin ser obligado a hacer cosa contraria a ella. En segundo lugar, se refiere al plano social, la libertad de culto, que se traduce en el derecho a practicar externamente la creencia hecha propia. Además, la integran la libertad de proselitismo o propaganda, la libertad de congregación o fundación, la libertad de enseñanza, el derecho de reunión y asociación y los derechos de las comunidades religiosas.

La libertad de culto, en cuanto manifestación externa de la libertad religiosa, comprende el derecho a mantener lugares de culto y a practicarlo, tanto dentro de recintos como en el exterior, siempre dentro de las limitaciones establecidas por el ordenamiento, sea por norma constitucional o norma legal. En este sentido, es el mismo texto constitucional que permite el libre ejercicio en la República de otros cultos -de la religión católica, siempre y cuando no se opongan a la moral universal, ni a las buenas costumbres. ${ }^{11}$

La libertad religiosa es una verdadera libertad fundamental con todos los atributos que le son propios, sea, es un derecho inherente a toda persona por su sola condición de tal; es anterior al Estado, es inviolable e imprescriptible.

El primer texto oficial de carácter internacional que se refiere a la libertad religiosa es la Declaración Americana de los Derechos y Deberes del Hombre, aprobada en

11. Véase voto de la Sala Constitucional n. ${ }^{\circ}$ 3173-93 


\section{ESPIGA}

Bogotá el 30 de marzo de 1948, cuyo artículo 3 dice:

"Toda persona tiene el derecho de profesar libremente una creencia religiosa y de manifestarla y practicarla en público y en privado".

En nuestro país no cabe duda de que el artículo 75 constitucional garantiza la libertad religiosa, al permitir el libre ejercicio de otros cultos distintos al católico, con la condición de que no se opongan a la moral universal ni a las buenas costumbres, siendo éstos, entonces, los límites genéricos de dicha libertad, además de los otros que son propios de toda libertad pública.

En otro orden de cosas, al decir la Constitución que la Iglesia católica es la del Estado, está indicando con ello que el mismo tiene una responsabilidad activa respecto de la misma.

En efecto, el artículo 75 de la Constitución dispone que el Estado debe contribuir al "mantenimiento" de la religión Católica, norma constitucional que no puede interpretarse en sentido restrictivo; por el contrario, se entiende que el Estado tiene una obligación, en sentido general, de cooperar con las diferentes confesiones religiosas que profesan los habitantes del país y en forma específica con la Iglesia Católica. Esta obligación constitucional consiste en posibilitar la formación religiosa en los centros docentes públicos, en la creación necesaria para su desarrollo y no concretamente en la asistencia de financiamiento económico. Con esto, la norma suprema considera de interés general la satisfacción de las necesidades religiosas, pese a la existencia de personas que no participen de ellas. Además, debe interpretarse, no como un indicador de parcialidad de la Constitución en beneficio de una confesión religiosa determinada, sino como un indicador de una realidad sociológica, cual es la mención expresa a la confesión indiscutiblemente más arraigada y extendida en nuestro país, lo que en ningún momento implica una discriminación por parte de los poderes públicos para las demás confesiones o para los ciudadanos aconfesionales. ${ }^{12}$

En nuestro medio la Sala Constitucional ha desarrollado dicho derecho de la siguiente forma:

12. Ibid. 


\section{El Estado}

y los principios

cristianos de justicia social

En nuestro ordenamiento constitucional existe una disposición singular que ha venido siendo ignorada por nuestros constitucionalistas, historiadores, políticos y operadores del Derecho en general y es la frase del artículo 74 que dice:

"Los derechos y beneficios a que este Capítulo se refiere son irrenunciables. Su enumeración no excluye otros que se deriven del principio cristiano de justicia social y que indique la ley; serán aplicables por igual a todos los factores concurrentes al proceso de producción, y reglamentados en una legislación social y de trabajo, a fin de procurar una política permanente de solidaridad nacional".

El antecedente de este artículo lo constituye el artículo 65 de la Constitución de 1871 cuando se le adicionó al capítulo de las garantías sociales en el año 1943, correspondiendo al artículo 65 que decía:

"Los derechos y beneficios a que esta Sección se refiere son irrenunciables. Su enumeración no excluye otros que se deriven del principio cristiano de Justicia Social, serán aplicables por igual a todos los actores concurrentes al proceso de producción y reglamentados en un Código Social y de Trabajo, a fin de procurar una política permanente de solidaridad nacional".

El capítulo de las garantías sociales no cabe duda que es de inspiración social cristiana, tanto porque así lo declaró el Presidente Calderón Guardia, como porque así lo ratifican diferentes fuentes.

Sobre este artículo 65 dijo el Presidente Calderón Guardia en su mensajealCongresoConstitucional del 16 de mayo de 1942:

"El artículo 65 del nuevo capítulo que os propongo declara que son irrenunciables los derechos y beneficios ahí establecidos. Ese es un postulado fundamental del Derecho del Trabajo que actualmente nadie discute. Por último, ni limitamos nuestro plan de reformas a los preceptos ya enunciados, sino que damos ancho campo para todos aquellos que se deriven del principio cristiano de Justicia Social, en orden a procurar una política permanente de solidaridad nacional". 


\section{ESPIGA}

En la Constituyente de 1949 en un primer momento se quiso dejar la frase indicando que "...se deriven del concepto de justicia social", o sea, eliminado el adjetivo cristiano, lo que al final no prosperó.

En cambio sí prosperó la moción según la cual "...otros que se deriven del principio cristiano e justicia social y que indique la ley..."

Tal cambio fue presentado por el Diputado Rojas Espinoza y se justificó en cuanto que el principio cristiano es sumamente vago, por lo que la moción es para que dicho principio sea definido por la ley.

A pesar del alegato del Diputado Volio Sancho, acérrimo defensor de la visión de la doctrina católica, de que el principio en referencia sí tiene un valor positivo así como contenido "ya que existen una serie de concepciones filosóficas perfectamente claras al respecto", es lo cierto que se aprobó la moción del Diputado Rojas E. quedando la redacción tal y como hoy día se encuentra, remitiendo a la ley, entonces, la definición del principio cristiano de justicia social. ${ }^{13}$

13. Actas Asamblea Nacional Constituyente. Imprenta Nacional, San José,1957, Tomo III, pág. 515.
De lo consignado hasta este momento, nuestro régimen constitucional se caracteriza por garantizar la libertad religiosa, por declarar que la religión católica es la del Estado y por declarar que la doctrina social de la Iglesia es la columna vertebral sobre la que se edifica la política social del país.

Procede a continuación que definamos la naturaleza jurídica de nuestro régimen en dicha materia $\mathrm{y}$, específicamente, que concretemos si nuestro Estado es un Estado confesional.

\section{Relaciones}

\section{de cooperación entre el Estado y la Iglesia en Costa Rica}

Para comenzar debemos de recordar que, además de las disposiciones constitucionales mencionadas, se ha dado a lo largo de nuestra historia una estrecha relación entre el Estado y la Iglesia Católica en diferentes órdenes, los que resumimos de la siguiente manera.

El matrimonio

El Código General de 1841, emitido por Carrillo, concibió al matrimonio como un sacramento que, 
como tal, se ajustaba a los cánones de la Iglesia Católica. Los tribunales eclesiásticos eran los únicos competentes para conocer del divorcio y éste no era vincular, ya que un divorciado no podía contraer nuevas nupcias mientras viviera su cónyuge.

Luego el Código Civil de 1888, que derogó la Parte Civil del Código General, estableció el matrimonio civil, aunque el católico continuó siendo civilmente válido. ${ }^{14}$

El Código de Familia promulgado en el año 1974, le sigue otorgando al matrimonio católico efectos civiles.

El concordato

del 7 de octubre de 1852

El primero y único Concordato que ha suscrito el Gobierno de Costa Rica con la Santa Sede, fue firmado el 7 de octubre de 1852 y luego derogado en el año 1884.

Este Concordato consta de 28 artículos y derogó toda ley, ordenanza o decreto que se le opusiere.

14. Sáenz Carbonell, José Francisco. Historia del Derecho Costarricense. Editorial Juricentro. San José, 1997 pág. 192 y ss.
En virtud del mismo Costa Rica ratifica su condición de Estado Confesional, puesto que su artículo 1 decía: "La Religión Católica Apostólica y Romana es la Religión del Estado en la República de Costa Rica, y se conservará siempre con todos los derechos y prerrogativas de que debe gozar la ley de Dios y las disposiciones de los Sagrados Cánones".

Acorde con lo anterior, el Gobierno de Costa Rica se comprometía a suministrar las dotaciones, y tanto los Obispos, como el Clero y el Pueblo tendrán libre comunicación con la Santa Sede Apostólica. (Art. 4).

En lo que a la materia educativa se refiere contiene tres artículos importantes.

El artículo 2 dice que: "En consecuencia, la enseñanza en las Universidades, colegios, escuelas $\mathrm{y}$ demás establecimientos de instrucción será conforme con la doctrina de la misma religión católica, al cual efecto los obispos y ordinarios locales tendrán la dirección libre de las cátedras de Teología, de Derecho canónico y de todos los ramos de enseñanza eclesiástica, y además de la influencia que ejercerán, en virtud de su ministerio sagrado, en la educación religiosa 


\section{ESPIGA}

de la juventud, velarán por que en la enseñanza de cualquiera otro ramo nada haya contrario a la religión y a la moral".

Es claro que por este artículo la educación adopta un carácter abiertamente confesional, esto es, tenía que estructurarse y llevarse a cabo en un todo conforme con la doctrina de la religión católica, a tal extremo que no solo habría enseñanza de la religión propiamente dicha, sino que la Iglesia velaría porque cualquier otro tipo de enseñanza no le fuere contrario.

También, según el artículo 3: "Los obispos conservarán asimismo su derecho de censura respecto a todos los libros o escritos que tengan relación al dogma, a la disposición de la Iglesia y a la moral pública, y el Gobierno de Costa Rica concurrirá, en cuanto se lo permita su autoridad y con los medios propios de ella, a sostener las disposiciones que los obispos tomarán conforme a los sagrados cánones para defender la religión y evitar todo lo que pudiera serle contrario".
En virtud de esta potestad, la Iglesia podía censurar cualquier libro o escrito que atentara contra su dogma o bien contra la moral pública, por lo que era una atribución muy amplia, que trascendía también el ámbito educativo ya que cualquier libro o texto que se fuera a emplear en la escuela podía ser objetado.

Finalmente, el artículo 20 indica que: "No se impedirá el establecimiento de monasterios o conventos de ambos sexos y de cualesquiera de los institutos aprobados por la Santa Sede. Las cosas relativas a seculares serán arregladas según lo disponen las leyes canónicas y las constituciones de las respectivas órdenes".

Este Concordato, que fue aprobado por el Gobierno de Costa Rica mediante la Ley n. ${ }^{\circ} 24$ del 2 de diciembre de 1852, tuvo una vida bastante efímera, ya que fue derogado mediante la Ley $n .^{\circ} 45$ del 28 de julio de 1884, que es una de las leyes que integra el grupo de leyes y decretos llamados liberales del año 1884, de sesgo abiertamente anticlerical según se estudia a continuación. 
La educación, vínculo estrecho entre el Estado y la Iglesia

La educación y el efecto de las leyes liberales

Mención especial merece el tema de la educación, en el cual la Iglesia se ha caracterizado por una participación muy dinámica a lo largo de la historia, relación que marca una fractura con la emisión de las llamadas leyes liberales de 1885, las que tuvieron un impacto directo en la tarea educativa-privada que venía desarrollando la Iglesia.

$\mathrm{Si}$ bien es cierto en dicho período se dieron cambios importantes en nuestro país y básicamente en la consolidación del Estado nacional en detrimento de las potestades de la Iglesia Católica, es lo cierto que tales leyes incidieron directamente en la conformación de la educación privada, puesto que era la Iglesia la que representaba los centros docentes privados más importantes que existían en ese momento.

Parte de los afectados fueron los miembros de la Compañía de Jesús quienes tenían bajo su dirección el Colegio de San Luis Gonzaga, quienes fueron sorprendidos el
18 de julio de 1884, a las nueve de la mañana con la orden de expulsión, dándoles por cárcel el Colegio, y siendo obligados a salir del país horas después. Ocho años seis meses duró dicho Colegio bajo el gobierno de los padres de la Compañía de Jesús.

Dicho Colegio se mantuvo cerrado el resto del año 1884, hasta 1885, cuando fue objeto de una nueva organización. 15

No es fin primordial de esta investigación analizar los pormenores de lo sucedido durante tales años por lo que remitimos a la lectura de la obra de Blanco Segura. ${ }^{16}$

Empero, en lo que al ámbito educativo se refiere debemos decir que las denominadas leyes liberales fueron de carácter religioso y en contra de manera específica de la Compañía de Jesús.

En efecto, mediante la ley n. ${ }^{\circ} 33 \mathrm{del}$ 22 de julio de 1884, se prohibió de manera absoluta el establecimiento de órdenes monásticas y comu-

15. González Flores, Luis F. Evolución de la Instrucción Pública en Costa Rica. Editorial Costa Rica, 1978. Pag. 406.

16. Blanco Segura, Ricardo.1884 El Estado, la Iglesia y las reformas liberales. Editorial Costa Rica, San José, 1984. 


\section{ESPIGA}

nidades religiosas, cualquiera que sea su clase y denominación.

Agrega la misma que "Se prohíbe al clero en el ejercicio de su ministerio, tomar ingerencia alguna en la dirección de la enseñanza que se da en los establecimientos costeados con fondos nacionales, o combatir dicha enseñanza por razón de ser exclusivamente laica" (Art. 6).

Mediante la ley n. ${ }^{\circ} 8$ del 5 de junio de 1894 se interpretó de manera auténtica la ley anterior al decir en su artículo 1:

"La prohibición establecida por el artículo primero de la ley de 22 de julio de 1884, comprende toda congregación religiosa, de hombres o de mujeres, de eclesiásticos o de seglares, ligados con cualquier género de votos que vivan o no en comunidad. Queda así interpretado el referido artículo".

Así las cosas, mediante Decreto del 18 de julio de 1884 el Presidente Próspero Fernández y su Ministro en el Despacho de Policita Bernardo Soto, expulsan del país a Monseñor Bernardo A. Thiel lo mismo que a la Compañía de Jesús establecida en Cartago.
El espíritu, la finalidad y el propósito de los hombres del 84 fue la eliminación de la Compañía de Jesús, por lo que dichas leyes, además de antirreligiosas y anticlericales, fueron leyes antijesuíticas. ${ }^{17}$

Los jesuitas llegaron a Costa Rica en 1875 para hacerse cargo del Colegio San Luis Gonzaga y pocos años después fueron expulsados del país.

No es sino hasta el año 1942 cuando mediante la ley n. ${ }^{\circ} 125$ del 30 de julio de ese año, se derogan las dos leyes dichas: la n. ${ }^{\circ} 33$ del 22 de julio de 1884 y la n. ${ }^{\circ} 8$ del 4 de junio de 1894.

Poco antes el 26 de setiembre de 1940, el Presidente Calderón Guardia y el Secretario Tinoco Castro promulgan el Decreto n. ${ }^{\circ}$ 13 permitiendo a los alumnos de los colegios privados presentar los exámenes de Bachillerato, en la misma forma establecida para los alumnos de los colegios oficiales, otorgándoles a dichos títulos de los colegios privados el mismo valor legal que los otorgados por los colegios oficiales, debiendo ser

17. Blanco Segura, op. Cit. Pg. 169 
comunicados a la Secretaría de Instrucción Pública.

En vista de que la anterior potestad se otorgó por decreto ejecutivo en el año 1941, se emite la Ley n. ${ }^{\circ} 359$ del 21 de agosto de ese año, permitiendo a los Colegios Particulares de Segunda Enseñanza expedir los títulos de Bachiller en Ciencias y Letras a los alumnos que hayan concluido y aprobado los cursos reglamentarios, siguiendo para ello los procedimientos del reglamento de Colegios de Segunda Enseñanza del 1 de diciembre de 1939. Es decir, se elevó a rango de ley lo que el Poder Ejecutivo había establecido a nivel de decreto.

Quedaron protegidos por dicha disposición los colegios que comprendan en su plan de estudios las materias exigidas en los institutos nacionales y que además cumplan con las condiciones del art. 1 incisos a) y e) de la Ley n. ${ }^{\circ} 20$ del 28 de diciembre de 1887, y que no son otras que son los siguientes: "que pasen anualmente al Ministerio de Instrucción Pública, nómina de los alumnos matriculados en cada uno de los cursos y el programa o programas de los mismos" y " que publiquen el resultado de los exámenes con las clasificaciones respectivas, consignándose igual- mente para constancia en libros llevados con la debida formalidad".

En fin, además de derogarse las leyes liberales, el gobierno de Calderón Guardia establece la enseñanza de la religión católica en las escuelas y sienta las bases del nuevo esquema de las relaciones entre el Estado y la Iglesia que se mantienen hasta la fecha, políticas que inciden de manera directa en el sistema educativo.

De manera especial, emite la ley n. ${ }^{\circ} 359$ del 21 de agosto de 1941, por medio de la cual se faculta a los colegios privados para extender títulos de bachiller en Ciencias y Letras a los alumnos que hayan concluido y aprobado en ellos los cursos reglamentarios, para lo cual debían sujetarse a los requisitos establecidos en el Decreto n. ${ }^{\circ} 3 \mathrm{del}$ 16 de febrero de 1943.

La trascendencia de la ley 359 consiste en que, por primera vez, se autoriza a los colegios privados a extender los títulos de bachiller, en tanto que, desde 1887, debían sus alumnos ir a someterse a las pruebas que elaboraban los colegios públicos. 


\section{ESPIGA}

Para tales efectos los colegios que deseaban acogerse a la nueva modalidad tenían que formular una solicitud a la Secretaría de Educación y, en caso de acogerse esta emite una resolución "reconociendo la validez oficial solicitada", acto que podría ser revocado.

El reconocimiento que otorga la Secretaría de Educación Pública implica que el Estado otorga validez oficial a favor de cada persona, y en cada caso concreto, a los estudios aprobados en planteles que no forman parte de su sistema educativo, en consideración a la similitud de los mismos con los oficiales.

No es de sorprenderse que a raíz de esta apertura del Estado hacia la educación religiosa y privada surgieran por esos años muchas instituciones de enseñanza regentadas por diversas congregaciones religiosas, como por ejemplo: el Colegio Nuestra Señora de Sión (Acuerdo Ejecutivo n. ${ }^{\circ} 38$ del 30 de marzo de 1943); el Colegio Seminario (Acuerdo Ejecutivo n. ${ }^{\circ} 38$ del 30 de marzo de 1943), el Colegio María Auxiliadora (Acuerdo Ejecutivo n. ${ }^{\circ} 40$ del 30 de marzo de 1949), el Colegio Los Ángeles (Acuerdo Ejecutivo n. ${ }^{\circ} 43$ del 30 de marzo de 1949), el Colegio Sagra- do Corazón de Jesús de Cartago (Acuerdo Ejecutivo n. ${ }^{\circ} 44$ del 31 de marzo de 1943), etc.

\section{La enseñanza de la religión} católica en los centros educativos

El presidente José Joaquín Rodríguez, poco después de asumir el poder, con el propósito de atenuar la situación de la Iglesia en materia educativa frente a las disposiciones de la Ley General de Educación Común, emite el Acuerdo n. ${ }^{\circ} 81$ del 13 de junio de 1890, que dispone en su artículo primero: "Eximir de la enseñanza obligatoria establecida por ley, en los días sábados, de las once de la mañana a las dos de la tarde, a los niños de las escuelas primarias y de las anexas a los colegios, para que puedan recibir en esas horas la instrucción religiosa, si sus padres y tutores así lo desean".

En su segundo artículo, dice: "Excitar al Obispo diocesano a fin de que reglamente esa instrucción y designe los maestros que especialmente hayan de darla, autorizándole, al propio tiempo para que les asigne la retribución correspondiente y haga uso con aquel objeto del local y útiles de las escuelas, con anuencia de las respectivas Juntas de Educación". 
Es decir, a pesar de que las leyes anticlericales están vigentes desde pocos años atrás, por este decreto se flexibiliza en un aspecto la posición estatal, consistente en que si bien es cierto no se enseña la religión en los establecimientos de enseñanza, se permite que puedan usar sus planteles y útiles, y se libera el día sábado para que, quienes así lo deseen, puedan recibir dicha enseñanza.

Luego, el día 2 de mayo de 1892, el presidente Rodríguez presenta un proyecto de ley al Congreso para restablecer en definitiva la enseñanza religiosa. Este no llegó a ser aprobado al clausurar el presidente Rodríguez dicho Congreso. Vistas estas circunstancias, el Poder Ejecutivo promulgó el Decreto n. ${ }^{\circ} 72$, del 4 de agosto de 1892, restableciendo en definitiva la enseñanza de la religión en las escuelas. Dice: "Establécese cese en las escuelas primarias del Estado la enseñanza del Catecismo Cristiano y la de la Historia Sagrada, impartida por los respectivos maestros, con la extensión que en el Reglamento, textos y programas de la Secretaría de Instrucción Pública previo informe de la autoridad eclesiástica" (Art. 1).
“Esta enseñanza se dará a los alumnos de ambos sexos cuyos padres, tutores o encargados no manifiesten por escrito y en la forma reglamentaria, decisión en contrario" (Art. 2). Luego, el artículo 3 derogó el citado acuerdo n. ${ }^{\circ}$ 81 del 13 de junio de 1890 .

Esta situación jurídica de la Iglesia Católica, en relación con el Sistema Educativo, se mantiene más o menos igual hasta los inicios de la década de los cuarenta del siglo $X X$, al dar inicio una nueva era de relaciones con la promulgación de leyes importantes que la definen claramente. En efecto, a partir de la Administración del Dr. Calderón Guardia (1940-1944), comienza una nueva era de relaciones entre la Iglesia y el Estado ya que de este momento en adelante la Iglesia vuelve a tener una injerencia de especial importancia en la educación costarricense.

La ley de mayor trascendencia que promulgó esta administración fue la Ley n. ${ }^{\circ} 125$, del 30 de julio de 1942, que derogó la ley n. ${ }^{\circ} 3$ del 22 de julio del año 1884 que, como se vio, lesionaba directamente los intereses de la Iglesia al prohibir el establecimiento de órdenes 


\section{ESPIGA}

monásticas, y toda injerencia en la educación, de tal suerte que, desde entonces, quedan sin efecto las restricciones sobre la intervención de la Iglesia en la educación y sobre la existencia de órdenes y congregaciones religiosas que son, como es sabido, las que dirigen y administran en forma directa los centros de enseñanza de la Iglesia.

Sin embargo, a principios de la Administración de Calderón Guardia, se promulgan otras leyes no menos importantes que conviene repasar. Así, mediante la Ley n. ${ }^{\circ}$ 21 del 10 de noviembre de 1940, se restablece la enseñanza obligatoria de la religión en las escuelas estatales.

En efecto, el artículo primero dice literalmente: "Establécese en las escuelas primarias del estado la enseñanza de la Religión que se dará a los niños cuyos padres, tutores o encargados, no manifiesten por escrito su voluntad que se les exima de recibirla", el artículo 2, a su vez, indica, que: "La enseñanza dicha se considerará de aprobación obligatoria para los efectos de grados, para todos los niños que no hayan sido eximidos de recibirla conforme al artículo anterior'"'.
Esta disposición comenzó a regir a partir del curso lectivo de 1941. Posteriormente, mediante el acuerdo ejecutivo $n .^{\circ} 165$, del 16 de enero de 1941, se pusieron en vigencia, desde esta fecha, los Programas de Religión para las escuelas primarias. Estos fueron sometidos a la aprobación de la "Secretaría" de Educación Pública, por el señor Arzobispo de la Arquidiócesis de San José. Estaban estructurados en tres ciclos durante los seis años que duraba la educación primaria. El primer ciclo calificado de elementalísimo, comprendía el primer grado de escuela y fue diseñado para algunas explicaciones sencillas que el maestro debía adaptar a la capacidad de los niños.

Esta disposición comenzó a regir a partir del curso lectivo de 1941. Posteriormente, mediante el acuerdo ejecutivo $n .^{\circ} 165$ del 16 de enero de 1941, se pusieron en vigencia, desde esta fecha, los Programas de Religión para las escuelas primarias. Estos fueron sometidos a la aprobación de la "Secretaría" de Educación Pública, por el señor Arzobispo de la Arquidiócesis de San José. Estaban estructurados en tres ciclos durante los seis años que duraba la educación primaria. El primer ciclo calificado de elementalísimo, comprendía el pri- 
mer grado de escuela y fue diseñado para algunas explicaciones sencillas que el maestro debía adaptar a la capacidad de los niños.

El segundo ciclo abarcaba el segundo y tercer grados, y la materia que comprendía era la propia del Catecismo abreviado de la Doctrina Cristiana, arreglado por el Consejo Catequístico Arquidiocesano y la Historia Sagrada del Antiguo y Nuevo Testamento, en forma elemental.

Finalmente, el tercer ciclo incluía los tres restantes años de la educación primaria. En este se señaló como libro de texto el "Catecismo Católico", publicado por la Editorial "San Francisco", en Padre Las Casas, República de Chile.

Más tarde, mediante el D.E. n. ${ }^{\circ}$ 3 del 7 de febrero de 1941, se establece que el número de horas lectivas de enseñanza será de dos a la semana. Reitera, además, que la asistencia a dichas clases de religión se considera obligatoria para todos los niños cuyos padres no soliciten por escrito al Director de la Escuela, al principio del curso, que se les exima de recibir esa enseñanza.
Ahora bien, la enseñanza de la religión, como se observa, se impuso originalmente solo para la educación primaria. No es sino hasta 1963 (D.E n. ${ }^{\circ} 3$ del 6 de abril de 1963) que se incluye, en forma optativa, por primera vez, en la educación media.

Otro reconocimiento importante que hizo el Estado lo es el contenido en el D.E. n. ${ }^{\circ} 23$ del 21 de octubre de 1941, que indica que los sacerdotes católicos que fueren nombrados como profesores de religión en los colegios de segunda enseñanza, o como maestros de religión en las escuelas primarias, serán considerados respectivamente como profesores de Estado en esa asignatura, y como maestros especiales con Certificado de Idoneidad para la enseñanza en dicha materia.

En el año 1975, se crea por primera vez un órgano especializado que se dio en llamar Asesoría General de Educación Religiosa (D.E. n. ${ }^{\circ}$ 5690-E del 16 de diciembre de 1975), como un organismo dependiente del Ministerio de Educación Pública, encargado de integrar la acción del Estado y de la Iglesia Católica, en la dirección, orientación y coordinación de la educación religiosa en todos los niveles y 


\section{ESPIGA}

ciclos del sistema educativo. Dicha Asesoría General estaba constituida por un Asesor General y por los Asesores Regionales destacados en las Direcciones Regionales de Enseñanza.

A la Asesoría General le correspondía, entre otras, las siguientes funciones: a) Planificar, dirigir y orientar, de manera dinámica y permanente, la educación religiosa en todos los niveles y ciclos del sistema educativo, b) Proveer el personal idóneo para todos los nombramientos de docentes en religión en aquellas plazas vacantes cuya provisión sea competencia directa del Ministerio de Educación Pública, c) Elaborar, a nombre del Episcopado Nacional Católico, y presentar al Ministerio de Educación Pública para su estudio y aprobación, los planes y programas de educación religiosa, etc.

Educación Religiosa, ubicado dentro de la Dirección General Académica de la División de Desarrollo Curricular.

Actualmente, esta Sección de Educación Religiosa está regulada en el D.E. n. ${ }^{\circ}$ 17051-MEP, del 3 de junio de 1986, a la que le compete integrar la Sección de la Iglesia y del Estado en la dirección, orientación y modalidades del sistema educativo. Corresponde, específicamente a esta sección desarrollar acciones de educación formal, no formal e informal en las áreas del desarrollo curricular, formación permanente del personal encargado de la educación religiosa y de investigación del currículum, tendientes al mejoramiento de la calidad de la educación.

Como funciones específicas de esta Sección se mencionan, entre otras: a) Definir la política, norma y procedimientos para la enseñanza de la religión, dentro del contexto de los planes de estudio de la educación formal y la acción de educación no formal, b) Elaborar y presentar, a la autoridad competente, para su estudio y aprobación, los planes y programas de educación religiosa, c) Mantener relación con el Seminario Central, Instituto Pedagógico de Religión $\mathrm{y}$ universidades que participan en la formación y capacitación de docentes de religión, a fin de unificar criterios, ch) Determinar las orientaciones metodológicas y los procedimientos evaluativos que permitan hacer efectivos los propósitos fundamentales de la educación religiosa y, finalmente, 
se asigna una atribución, de suyo importante, consistente en "Proponer los candidatos para el nombramiento y traslados de Profesores en Educación Religiosa, para lo cual tanto los funcionarios regionales como los de la sede central deberán atender las proposiciones que en cada caso haga el director de la Sección Religiosa", es decir, que el nombramiento de los profesores de religión es atribución exclusiva de esta Sección, lo mismo que su remoción y traslado. Este caso, por cierto, es único en nuestro sistema educativo, ya que las decisiones de esta sección en esta materia prevalecen inclusive sobre las propias del Ministro de Educación.

Otro ejemplo que demuestra la estrecha relación que venimos insistiendo es el siguiente: En virtud de la norma presupuestarla n. ${ }^{\circ} 102$ de la Ley de Presupuesto Extraordinario de la República del año 1981, "los sacerdotes que hayan ingresado a desempeñar algún puesto, en propiedad en el Magisterio Nacional, tendrán derecho a que se les computen, para efectos de pensión y aumentos anuales, los años anteriores en que han ejercido su ministerio eclesiástico. Estos años se tomarán en cuenta a partir de su ingreso al estado clerical". Luego, mediante Ley n. 6997 del 27 de agosto de 1985, se reformó el artículo 2 de la Ley de Pensiones y Jubilaciones del Magisterio Nacional, el que dice en su inciso d) que tendrán derecho a acogerse a la jubilación ordinaria los servidores que se hallen en cualquiera de los siguientes casos: "Quienes sean sacerdotes y hayan cumplido treinta años de ejercicio eclesiástico, computados a partir de la ordenación sacerdotal, y quince años de servicio en el Magisterio Nacional". También indicó esta ley en su transitorio que "los sacerdotes que a la promulgación de esta ley tengan sesenta años o más de edad y que hayan completado diez años de servicio en la docencia nacional, podrán acogerse a la pensión en los términos que señala la ley n. ${ }^{\circ} 2248$ y sus reformas".

En suma, una de las misiones naturales más importantes de la Iglesia es la libertad de educar y la libertad de abrir escuelas de cualquier naturaleza y orden, misión que el Estado costarricense le ha respetado a lo largo de la historia. 


\section{ESPIGA}

La missio canónica

y la enseñanza de la religión

Un tema que en los últimos años está causando roces entre el Estado y la Iglesia se refiere a la autorización que debe otorgar la Conferencia Episcopal para el personal docente que pretenda impartir la materia de religión, la que ha llegado a denominarse como la missio canónica.

Dicha licencia deriva directamente del Código de Derecho Canónico, siendo el canon 805 el que dice:

"El Ordinario del lugar, dentro de su diócesis, tiene el derecho de nombrar y aprobar los profesores de religión, así como de remover o exigir que sean removidos, cuando así lo requiera una razón de religión o moral".18

De manera congruente con el Derecho Canónico, el artículo 34 del Reglamento de la Carrera Docente (D.E. n. ${ }^{\circ}$ 2235-EP del 4 de febrero de 1972), consagra la missio canónica al decir en lo que interesa que:

18. Código de Derecho Canónico. Ediciones Universidad de Navarra, Pamplona,1983.
"Para la selección del personal dedicado a la educación religiosa, será requisito indispensable la autorización previa que extenderá la Conferencia Episcopal".

El problema legal que se ha presentado consiste en que la Universidad Nacional imparte la carrera de teología y enseñanza de la religión pero no goza de la oficialidad de la Iglesia, siendo la única carrera que reconoce para esos efectos la que imparte la Universidad Anselmo Llorente que es la universidad católica regentada por la Conferencia Episcopal.

Ha correspondido a la Sala Constitucional dilucidar tal controversia por presunta discriminación y por negación al derecho del trabajo.

En el año 2003, la Sala se pronunció sobre un amparo en la que la recurrente alegó que la Conferencia Episcopal no le otorgó la autorización para impartir clases de religión a pesar de que lo venía haciendo desde hace varios años.

La razón de la denegatoria obedeció a que, si bien la recurrente era viuda, vivía en unión libre, lo que es una irregularidad sacramental 
y no puede ser candidata para enseñar la doctrina de la iglesia en torno al sacramento del matrimonio y su testimonio no es edificante para la comunidad educativa.

La Sala rechaza el amparo aduciendo que:

"Para esta Sala está claro que la enseñanza de la religión católica es una actividad evangelizadora de la Iglesia Católica, no otra interpretación puede desprenderse del artículo 75 de la Constitución cuando dice "La Religión Católica, Apostólica, Romana, es la del Estado, el cual contribuye a su mantenimiento...", y esa labor se concreta en el artículo 34 del Reglamento de la Carrera Docente cuando requiere una autorización de la Conferencia Episcopal Nacional para el ejercicio de la docencia de la religión católica". ${ }^{19}$

Dicho criterio es el correcto, porque ciertamente lo que se enseña es religión católica -no teología o moral- por lo que solo los que la Iglesia estima idóneos, según sus propias regulaciones, pueden impartir dichas clases, puesto que la Educación Religiosa es una tarea evangelizadora de la Iglesia, y en consecuencia quien opta por laborar como docente de Educación Religiosa no va en nombre propio, sino en nombre de la Iglesia que le envía a evangelizar.

En otro caso similar una docente acudió a la Sala por cuanto no se le prorrogó su nombramiento y adujo que se le violentó el derecho al trabajo.

Ese Tribunal de manera contundente declaró:

"Este requisito administrativo no es contrario al derecho al trabajo que está en la Constitución Política, sino que se trata de uno de los requisitos de legalidad que debe cumplir toda persona que aspire a un puesto como el que la recurrente ostentaba, el derecho al trabajo no es absoluto, está sujeto a condiciones y limitaciones, si bien es cierto este Tribunal ha señalado que no se puede sustituir un interino por otro interino, eso debe entenderse así en un contexto en que la persona que había estado nombrada sigue cumpliendo todas las condiciones que el puesto requiere, en el presente caso eso no sucedió, porque se incumplió un requisito para poder trabajar en ese

19. Sala Constitucional, voto $3684-03$ 


\section{ESPIGA}

puesto. Siendo que la recurrente no cumplió con un requisito que la Administración exige para llevar a cabo el nombramiento, no procedía la prórroga automática del nombramiento y en consecuencia lo procedente es declarar sin lugar el recurso". 20

Finalmente, en otro voto la Sala analizó con mayor profundidad la constitucionalidad del artículo 34 indicado concluyendo que no lesiona a la Carta Magna. Este caso tiene la particularidad de que se refería a una persona que pretendía se nombrado en el puesto de Asesor Regional de religión, para lo cual requería de la autorización de la Conferencia Episcopal, la que no se la dio por faltarle requisitos.

“De este modo, resulta objetivo y razonable exigir a quien impartirá una religión determinada cumplir con los requisitos técnicos que demuestren que difundirá su religión según los cometidos de ésta, y que encontrar dichos atestados no le corresponde al Estado propiamente. Así, considera la Sala que no existe infracción constitucional alguna entre el Estado y la Conferencia Episcopal, como organización católica que se

20. Sala Constitucional, voto $4458-03$ avoca a comprobar los requisitos en materia de su orientación religiosa, para la escogencia de los profesionales, pues lo que existe aquí es un tipo de relación de servicio público especial, según se ha razonado arriba". 21

No solo eso, sino que la enseñanza de la religión en los centros docentes es una forma de estimular la educación católica como la del Estado, por lo que de manera igualmente lógica la missio solo la puede conceder la propia Iglesia.

“De este modo, la disposición reglamentaria que impugna el accionante frente a la norma constitucional no produce roce alguno, por el contrario se actúa conforme al mandato constitucional de dar "mantenimiento" a la Religión Católica, Apostólica y Romana, todo lo cual no excluye que en materia de formación religiosa, de otro orden que la del Estado, se pueda impartir en otros centros educativos privados".

Concluye la Sala cerrando la discusión así:

"Sin embargo, para los efectos de la selección de personal que 
impartirá una determinada filosofía religiosa no puede recaer en las manos del Estado, pues la misio canónica debe recaer técnicamente en un ente con mayor afinidad en materia religiosa que la de un ente público que intenta impartir esa filosofía a los fieles". 22

En suma, desde el punto de vista jurídico el requisito de la missio es no solo constitucional sino que, por lógica y definición, es necesario y debe concederla la Iglesia, puesto que estamos frente a una labor evangelizadora que, como tal, debe estar sujeta al control de la titular de dicha labor que no es otra que la misma Iglesia.

La Iglesia católica y la

Constituyente de 1949

En la Asamblea Nacional Constituyente de 1949, la Iglesia Católica tuvo una activa participación por medio de su prelado. Esto coadyuvó, no hay duda, a configurar en mucho el régimen jurídico de la educación que hoy recoge nuestra Constitución Política.

En efecto, Baudrit Solera y otros presentaron una moción para que el artículo 67 de la Carta de 1871 que dice: La enseñanza primaria es obligatoria, gratuita y costeada por la Nación. La dirección de ella corresponde al Poder Ejecutivo se lea así: "La educación es función esencial del Estado, el cual está en la obligación de crear las instituciones y servicios suficientes para atender a las necesidades educacionales y culturales del país". Fue en primera instancia aprobada por la Asamblea Constituyente en la sesión del 23 de setiembre de 1949 (Acta n. ${ }^{\circ} 156$ ).

El diputado Volio Sancho fue uno de los que más radicalmente se opuso a esta redacción, aduciendo, entre otras cosas, que de aprobarse así se le estaría dando a la educación un carácter fundamentalmente estatista, con los perjuicios consiguientes para la iniciativa privada, que quedaría en segundo plano. "Está bien que la acción del Estado se haga sentir en materia educacional, siempre y cuando esa acción sea supletoria de la iniciativa particular", decía Volio Sancho (Acta n. ${ }^{\circ}$ 156). Por estas razones, propuso la siguiente redacción. "Todos los habitantes de la República tienen derecho a recibir educación integral. Los

22. Ibid. 


\section{ESPIGA}

padres están obligados a educar a sus hijos. Es deber del Estado facilitar la educación, dándole atención preferente".

A la Iglesia le preocupó este artículo, lo que motivó que el Arzobispo Monseñor Víctor Manuel Sanabria M., le enviara al diputado Volio Sancho el siguiente telegrama, que es lo suficientemente elocuente por sí solo. Dice: "Señor Licenciado don Fernando Volio Sancho, Diputado a la Asamblea Nacional Constituyente. Cartago. En mi calidad de Arzobispo, representante de los intereses católicos de nuestra patria y de la concepción cristiana de la Educación, tengo el honor de dirigirme a Ud. para rogarle muy encarecidamente que en la sesión próxima de la Honorable Asamblea Nacional Constituyente, se sirva pedir la revisión del artículo, ya aprobado, en el que se adopta un criterio totalitario de las funciones que en orden a la Educación corresponden al Estado, y que priva a los padres de familia, cualquiera que sea su credo, contrariando el Derecho Natural, de derechos que en justicia no hay autoridad humana que los pueda privar. Me dirijo a Ud., que en sus actuaciones en la Asamblea
Nacional Constituyente ha dado pruebas de que ha querido ser fiel intérprete de la voluntad de los ciudadanos católicos que lo eligieron y consecuente con los principios de su conciencia cristiana y de sus convicciones democráticas".

A su vez, los Obispos de la Provincia Eclesiástica de Costa Rica, en memorándum que enviaron a la Asamblea Constituyente, en el mes de febrero de 1949, se expresaron de la siguiente manera: "Por derecho natural la educación es función de la familia no del Estado, bien que es cierto que al Estado le corresponde una obligación primordial y subsidiaria en esta materia... El Estado debe velar sobre las condiciones generales de la educación en todos los institutos, también en los particulares, pero esta vigilancia no debe tener por objeto coartar irracionalmente la libertad de enseñanza, sino lograr que el uso de ella no ceda en perjuicio de los intereses de la cultura nacional".

Luego, en otro párrafo, agregan: "de hecho, puesto que no prejuzgamos intencionalmente, se constituirla al Estado en único soberano dispensador de la ciencia y de 
la cultura, su pretexto de insistir en las obligaciones de éste para con aquéllas, y se daba golpe de gracia o punto menos a aquel gran principio jurídico, costarricense como el que más, de la libertad de enseñanza..." En la sesión del 26 de setiembre, el diputado Volio Sancho presentó la revisión correspondiente, la que fue desechada. No es sino en la sesión del 21 de octubre de 1949 (Acta n. ${ }^{\circ}$ 172) que un grupo de 33 diputados -incluyendo al Lic. Volio Sancho y varios de los autores de la disposición- presenta la moción para que sea derogado este artículo tal y como fue aprobado, moción que fue aprobada.

Como se puede observar, la Iglesia Católica fue un factor determinante para que se aboliera una disposición que ya había sido aceptada por la Asamblea Constituyente, por considerarla lesiva a sus intereses y a su concepción de la educación, y que podía dar base a que se afectara la libertad de enseñanza y a que se institucionalizara un sistema educativo estatista.

En suma, la Iglesia estimó perjudicial esta disposición a los principios jurídicos y católicos según los cuales, es a los padres de familia, al hogar, a quienes corresponde, originariamente y con mejores títulos que los del Estado, el derecho y el deber de educar a la prole, ya que ese deber y ese derecho son consustanciales con la patria potestad, anteriores y preferentes a los de la sociedad civil o del Estado.

Educación religiosa

y libertad de culto

El artículo 75 de nuestra Carta Magna, como se indicó, garantiza la libertad religiosa y de culto, libertad que en ciertos casos puede entrar en conflicto con el derecho a la educación $\mathrm{o}$, al menos, en la forma que el sistema educativo ofrece el servicio educativo, por lo que conviene hacer un repaso sobre la manera en que la Sala Constitucional ha resuelto dicho choque de derechos fundamentales.

Resulta interesante destacar el caso de un centro educativo público de Pérez Zeledón llamado Escuela Sagrada Familia. Su escudo fue diseñado hace más de 20 años y para sus autoridades, es representativo de los valores de la comunidad, que es un caserío también denominado Sagrada Familia. 


\section{ESPIGA}

Al ser el escudo parte del uniforme, portar el mismo es obligatorio.

Sin embargo, un grupo de padres de familia alegó ante la Sala Constitucional que el deber de portar un escudo con motivos religiosos lesiona sus convicciones religiosas.

La Sala Constitucional, mediante el voto 8387-99 declaró con lugar el amparo interpuesto.

Para tales efectos, la Sala ratificó lo resuelto en un voto anterior (391499 de las 16:27 horas del 20 de mayo de 1999) indicando que:

"A la niña amparada le asiste el derecho a no ser obligada a practicar actos de culto o a recibir asistencia religiosa contraria a sus convicciones personales. Dado que una de las creencias religiosas de la amparada se refiere al mandato de Dios de no hacer uso de imágenes o ídolos de connotación religiosa, la obligación de portar un escudete con la imagen de la Virgen de Las Mercedes constituye una imposición contraria a sus convicciones y al culto religioso que practica. En virtud de que en el Centro Educativo Las Mercedes la omisión de portar el escudete de la institución es sancionada en los términos indicados en el artículo 76 del Reglamento de Evaluación de los Aprendizajes, la amparada ha sido obligada a portar la imagen de la Virgen de Las Mercedes en su uniforme escolar, situación que resulta violatoria de la libertad religiosa y de culto, garantizada en los artículos 75 de la Constitución Política, 14 de la Convención de Naciones Unidas sobre los Derechos del Niño, 24 del Pacto Internacional de Derechos Civiles y Políticos, artículo 13.3 del Pacto Internacional de Derechos Económicos, Sociales y Culturales y 36 de la Ley Fundamental de Educación."

Así las cosas, ningún centro educativo puede obligar a sus alumnos a portar en el uniforme imágenes de carácter religioso que vayan en contra de las convicciones de los alumnos o de sus padres.

Tema ligado al anterior es el relacionado con quienes practican otras convicciones religiosas que les exige guardar el día sábado y las instituciones educativas contemplan actividades académicas dichos días. Por ejemplo, que la Universidad de Costa Rica programa el examen de admisión esos días; las pruebas nacionales del 
Ministerio que se lleven a cabo los sábados o en general actividades de los centros educativos que se practican dichos días.

Un amparo fue declarado con lugar por cuanto la Universidad de Costa Rica programa los exámenes de reposición los sábados, lo que le restringía el derecho de libertad religiosa a la recurrente.

"En efecto, la negativa de la Universidad de Costa Rica a realizar un examen de reposición a la recurrente pese que su religión limita la realización de actividades educativas los días sábados, afecta el derecho a practicar los actos de culto propios de una creencia de la recurrente y como se dijo en el considerando anterior ese es uno de los elementos de la libertad religiosa. Estima esta Sala que la negativa de las autoridades universitarias a realizar un examen de reposición resulta irrazonable, dado que la realización de un examen extraordinario o de reposición, para la recurrente no sólo no afecta el debido funcionamiento del centro universitario recurrido, sino además se trata de una práctica usual y reconocida por toda la población estudiantil y docente." 23
Agrega la Sala que este tipo de restricciones, no solo lesiona la libertad de culto, sino que representa una injerencia externa de los entes públicos en las prácticas religiosas.

“Así las cosas, se evidencia en el caso concreto que la Universidad de Costa Rica ha irrespetado ese deber de cooperación y de no injerencia externa por parte de los poderes públicos en las actividades de la creencia religiosa de la recurrente. En esa medida el ejercicio de su libertad religiosa de actuar conforme con determinado credo se ha visto restringida, condicionada y obstaculizada. La amparada se ha visto imposibilitada a desarrollar actividades que constituyen actos manifestaciones o expresiones de sus creencias religiosas." 24

Para el año 2003 la UCR programó el examen de admisión de los estudiantes del Instituto Jaim Weizman, que es judío, para un sábado, día que celebran las festividades de la religión judía. La Sala declaró con lugar el amparo de la siguiente forma.

24. Ibid.

23. Sala Constitucional, voto $3018-02$ 
"En efecto, la negativa de la Universidad de Costa Rica a variar la fecha en que se programó el examen de admisión de la UCR para este año -28 de setiembre-, pese que coincide con la celebración del Año Nuevo Judío (Fiesta de Rosh Hashaná en hebreo) -27 y 28 de setiembre-, afecta el derecho de practicar los actos de culto propios de la creencia que profesan los estudiantes del Instituto Dr. Jaim Wieznman -religión judía-, y como se dijo en el considerando anterior ese es uno de los elementos que integran la libertad religiosa. Estima esta Sala que la negativa de las autoridades universitarias a acceder a la solicitud realizada tanto por el Director General del Instituto Weizman, así como por el Rabino Principal del Centro Israelita Sionista resulta irrazonable, dado que los recurridos fueron puestos sobre aviso de los hechos descritos anteriormente, aproximadamente con dos meses de antelación a la fecha en que se programó el examen referido, de manera que contaban con tiempo suficiente para tomar las medidas correctivas necesarias". 25

Sin embargo, también se ha dado el caso en que la Sala declaró sin

25. Sala Constitucional, voto 13624- 03 lugar un amparo en que se alegó que una de las pruebas de noveno año se hará el día sábado 15 de octubre y el recurrente guarda ese día por motivos religiosos, pero no logró concretar las creencias religiosas que supuestamente se le estaban lesionando, puesto que no todos deben guardar el día sábado, por lo que ante semejantes inconsistencias la Sala optó por denegar el amparo. 26

Otro tema similar es el referente a la obligación o no de recibir las clases de religión católica en las escuelas y colegios públicos, obligación que deriva del artículo

26. “Ahora bien, la aplicación del antecedente citado no acarrea las mismas consecuencias en este amparo, pues según se desprende de los autos, el recurrente acude a este Tribunal considerando que se lesionan sus creencias religiosas, pero ni siquiera indica cuáles son éstas, pues no son todas las religiones las que amparan como sagrado el día sábado. Por otro lado, en la gestión que presentó el amparado ante la autoridad recurrida y sólo dos días antes de presentar este recurso, por lo que acudió prematuramente, solicitó que se le trasladaran las pruebas de español y ciencias por razones religiosas, sin indicar su credo o el motivo, toda vez que los exámenes señalados por el recurrente ni siquiera estaban programados para un día sábado". Sala Constitucional, voto 160282005 
210 del Código de Educación que dice:

"Cada grado o sección de las escuelas de primera enseñanza de la República, sin excepción, recibirá semanalmente dos horas lectivas de enseñanza religiosa. La asistencia a las clases de Religión se considerará obligatoria para todos los niños cuyos padres no soliciten por escrito al Director de la escuela que se les exima de recibir esa enseñanza. Los Directores comunicarán a los respectivos Visitadores o Inspectores la lista de esas solicitudes y las archivarán en debida forma".

En un caso fallado en el mes del mes de agosto del 2006, el recurrente acusó que el Director de la Escuela Joaquín García Monge dispuso que los padres de los educandos que no reciben lecciones de Educación Religiosa, después de las vacaciones de medio año deberán retirar a sus hijos durante el tiempo que se impartan las lecciones de religión, lo cual es claro que resulta incompatible con el Derecho de la Constitución. El Director, frente al amparo, retiró la media, pero el recurso fue declarado con lugar. ${ }^{27}$

27. Sala Constitucional, voto $n .^{\circ} 11328-06$
Del anterior caso se puede extraer el principio general de que del hecho de que el alumno se niegue a recibir la materia de religión, ello no autoriza al centro educativo a adoptar medidas que puedan exponer la seguridad y permanencia de los alumnos en el centro educativo.

\section{CONCLUSIONES}

El artículo 75 constitucional declara el principio de que la Religión Católica es la del Estado y el principio de libertad de cultos.

Por otro lado, según jurisprudencia de la Sala Constitucional, al interpretar los alcances de este artículo, el Estado debe cooperar con las demás confesiones, con lo cual extiende la literalidad de dicho numeral, pero con lo que le da a este artículo una concepción más moderna en lo referente a la relación entre el Estado y el fenómeno religioso.

"El atículo 75 de la Constitución dispone que el Estado debe contribuir al mantenimiento, la norma constitucional no puede interpretarse en sentido restrictivo por el contrario, se entiende que el Estado tiene una obliga- 


\section{ESPIGA}

ción, en sentido de cooperar con las diferentes confesiones religiosas que profesan los habitantes del país y en forma específica con la Iglesia Católica" (voto 3173-93).

A la luz de los conceptos expuestos ut supra nuestro Estado no es confesional, por cuanto no se da una confusión entre la religión y el Estado o, mejor dicho, la religión no invade la política o la esfera del Estado; por otro lado el estímulo que el Estado puede y debe dar no es exclusivo para con la Iglesia Católica.

Tampoco es un Estado laico, por cuanto no busca una separación total con la Iglesia o el fenómeno religioso en general, o sea, no asume un rol de total indiferencia y separación con la Religión, relegando dicha materia a la sociedad civil. Por el contrario, es un Estado que ve con interés las inclinaciones religiosas de la sociedad, las que apoya y estimula.

Consecuentemente, el artículo 75 constitucional interpretado a la luz de la jurisprudencia de la Sala Constitucional define un Estado Democrático de Libertad Religiosa por cuanto, a pesar de indicar que la Religión Católica es la del Estado, a la que contribuye a su mantenimiento, es lo cierto también que no solo garantiza la libertad religiosa sino que, por igual, debe cooperar y estimular otras confesiones distintas a la católica.

Gracias a tal interpretación, se supera la tradicional dicotomía entre confesionalismo y laicismo y se evoluciona hacia una nueva síntesis que identifica a ese nuevo Estado Democrático de Libertad Religiosa, el que gira en torno a la idea de cooperación entre el Estado y las confesiones religiosas, es decir, que el Estado costarricense debe tener en cuenta las creencias religiosas de la sociedad y mantener relaciones de cooperación no solo con la Iglesia Católica sino también con las demás confesiones en un nivel de igualdad jurídica.

Tal concepción deriva no de la literalidad del artículo 75 sino de la interpretación extensiva que le ha dado a dicho artículo la Sala Constitucional, que estimamos correcta y que supera una eventual lucha ideológica entorno al Estado Confesional. 
Tal vez el ejemplo más directo que demuestra esta nueva evolución lo constituye la reforma al Código de Trabajo, permitiendo a los practicantes de religiones distintas de la católica, solicitar a sus patronos el otorgamiento de los días de celebración religiosa propios de su creencia como días libres y el patrono estará obligado a concederlo. Cuando ello ocurra, el patrono y el trabajador acordarán el día de la reposición, el cual podrá rebajarse de las vacaciones (reforma al artículo 148, aprobada mediante Ley n. 7619 del 24 de julio de 1996).

Nuestro régimen jurídico ostenta una particularidad muy importante, cual es la de haber elevado a rango constitucional la doctrina social de la iglesia, como doctrina inspiradora y articuladora de la legislación social, de tal suerte que, integrando las disposiciones constitucionales, debemos concluir no otra cosa que el aparente confesionalismo de nuestro Estado responde más bien a una concepción filosófica de la vida. Es decir, que el mismo ha asumido dicha concepción como proyecto filosófico-político, más que asumir una religión propiamente dicha, lo que no tendría un efecto práctico alguno.

Finalmente, tomando en consideración la evolución jurídica del confesionalismo en nuestro país y la interpretación extensiva que la Sala Constitucional ha dado a tal disposición, es recomendable, a no dudarlo, que el Gobierno de Costa Rica suscriba un concordato con la Santa Sede con el fin de definir más adecuadamente la condición jurídica de la Iglesia en nuestro medio, dando mayor seguridad a la misma, vía que en materia educativa podría significarle a la Iglesia un avance y consolidación importantes.

\section{BIBLIOGRAFÍA}

Asamblea Nacional Constituyente. (1957). Actas, San José: Imprenta Nacional

Borja. Rodrigo. (1998). Enciclopedia de la Política. México: Fondo de Cultura Económica.

Blanco Segura, Ricardo. (1984). El Estado, la Iglesia y las reformas liberales. San José: Editorial Costa Rica,

Código de Derecho Canónico. (1983). Pamplona: Ediciones Universidad de Navarra.

González Flores, Luis F. (1978). Evolución de la Instrucción Pública en Costa Rica. San José: Editorial Costa Rica. 


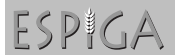

Universidad de Navarra. (1983). Derecho Eclesiástico del Estado Español, Pamplona: Ediciones Universidad de Navarra.

Viladrich, Pedro-Juan. (1997). "Los principios informadores del Derecho Eclesiástico Español" en Sáenz Carbonell, José Francisco. Historia del Derecho Costarricense. San José: Editorial Juricentro.

Zanone, Valerio. (1991). "Laicismo". En Diccionario de Política, II T. Bobbio y otros. México: Siglo Veintiuno Editores. 